\title{
Anal Invasive Squamous Cell Cancer and Human Papillomavirus Distribution in HIV-Infected and Non-HIV-Infected Individuals
}

\author{
Laila Darwich ${ }^{1,2}$, Sebastián Videla1,3*, Mari-Paz Cañadas ${ }^{1,4}$, Josep Coll1,5, Boris Revollo', \\ Marta Piñol ${ }^{1}$, Francesc García-Cuyás ${ }^{1}$, Eva Castella1, Bonaventura Clotet1,5,6,7, \\ Guillem Sirera1,5 \\ ${ }^{1}$ Lluita Contra La SIDA Foundation, University Hospital Germans Trias i Pujol, Badalona, Spain \\ ${ }^{2}$ Departament de Sanitat i d'Anatomia Animals, Faculty of Veterinary, Universitat Autònoma de Barcelona \\ (UAB), Bellaterra, Spain \\ ${ }^{3}$ Department of Experimental and Health Sciences, Faculty of Health and Life Sciences, Universitat Pompeu \\ Fabra, Barcelona, Spain \\ ${ }^{4}$ General-Labco, Barcelona, Spain \\ ${ }^{5}$ HIV Clinical Unit, University Hospital Germans Trias i Pujol, Universitat Autònoma de Barcelona (UAB), \\ Badalona, Spain \\ ${ }^{6}$ Retrovirology Laboratory IrsiCaixa Foundation, University Hospital Germans Trias i Pujol, Badalona, Spain \\ ${ }^{7}$ Universitat de Vic, Vic, Spain \\ Email: *svidela@flsida.org, ${ }^{*}$ sebastia.videla@upf.edu, ${ }^{*}$ svidela@esteve.es
}

Received 22 August 2014; revised 12 September 2014; accepted 5 October 2014

Copyright (C) 2014 by authors and Scientific Research Publishing Inc.

This work is licensed under the Creative Commons Attribution International License (CC BY).

http://creativecommons.org/licenses/by/4.0/

c) (i) Open Access

\section{Abstract}

Invasive-squamous-cell-cancer (ISCC) of the anal canal is an uncommon disease. Human papillomavirus (HPV) is the etiological agent of most of types of ISCC. The incidence of ISCC has been increasing in HIV-infected individuals, even after the introduction of highly active antiretroviral therapy. The aim of this study was to analyze biopsy specimens from patients diagnosed with ISCC at a tertiary hospital from 1983 to 2012 in order to detect HPV-DNA. Methods: Formaldehydefixed, paraffin-embedded specimens from patients with ISCC underwent HPV-DNA genotyping using multiplex PCR assay. Results: A total of 31 cases were collected; 10 were HIV-infected (9 men, 1 woman) and 21 non-HIV-infected (11 men, 10 women). HPV infection was detected in 87.5\% (7/8) of the HIV-infected patients (DNA from 2 biopsies was degraded) and $76.2 \%(16 / 21)$ of non-HIVinfected individuals. Multiple-type infections were only found in $28.6 \%(2 / 7)$ of the HIV-infected

${ }^{*}$ Corresponding author.

How to cite this paper: Darwich, L., et al. (2014) Anal Invasive Squamous Cell Cancer and Human Papillomavirus Distribution in HIV-Infected and Non-HIV-Infected Individuals. International Journal of Clinical Medicine, 5, 1155-1160.

http://dx.doi.org/10.4236/ijcm.2014.519148 
patients (no multiple-type infections in non-HIV-infected individuals). The most prevalent type was HPV-16: $50 \%(4 / 8)$ in the HIV-infected group (57\% [4/7] of the HPV-positive samples) and $66.7 \%(14 / 21)$ in the non-HIV-infected group $(87.5 \%(14 / 16)$ of the HPV-positive samples). Remarkably, 37.5\% (3/8) of the HIV-infected group had high-risk HPV types not included in the vaccines (HPV-33, 51, 52, and 66) compared with $4.8 \%$ in the non-HIV-infected group $(1 / 21, \mathrm{HPV}-52)$. All cases of anal ISCC in HIV-infected patients were recorded in the highly active antiretroviral therapy era. Conclusion: HIV-infected patients presented anal ISCC with a higher proportion of high-risk HPV types not covered by the conventional vaccines than non-HIV-infected individuals.

\section{Keywords}

Human Papillomavirus, Anal Invasive Squamous Cell Cancer, HIV Infection

\section{Introduction}

Anal cancer is relatively less common than cervical cancer [1]. However, its incidence is rising annually in both genders in the general population [2]-[4]. Rates of anal cancer in at-risk groups, principally men who have sex with men (MSM) and persons infected by the human immunodeficiency virus (HIV), are considerably higher than those described in the healthy population [5]-[8]. Although the incidence of other virus-associated malignancies has decreased in HIV-infected patients since antiretroviral therapy (ART) became available, the incidence of anal cancer has not. In fact, the incidence in HIV-infected MSM is estimated to be 80 times higher than the incidence in men in the general population [9]-[11]. Prolonged survival with highly active ART (HAART) is likely to lead to a further increase in the incidence of anal cancer among HIV-infected individuals [11].

The etiological agent of high-grade squamous intraepithelial lesions (HSIL) in the genitals, anus, and oropharynx is the human papillomavirus (HPV), mainly the oncogenic high-risk genotypes (HR-HPV). HSIL was recently reported to directly progress to anal cancer [9]. Most studies show that ART has had little effect on reducing the frequency of HSIL [12]-[14], and, consequently, on the appearance of squamous cell cancer (SCC) of the anal canal and perianal region. HIV infection is a key risk factor for anal SCC owing to the high risk of contracting coinfections with HPV [5] [6] [9] [10]. Anal HPV infections are widespread among HIV-infected MSM, and the type most frequently associated with anal SCC is HPV-16 [1] [10] [12]. Given the current recommendation to administer HPV vaccine for the prevention of HPV-associated anal lesions in specific groups, such as MSM [4] [14], it is important to document the burden of anal cancer in these risk groups.

Few studies have focused on anal invasive squamous-cell cancer (ISCC) in HIV-infected patients during the HAART era. We have analyzed the incidence of anal ISCC during the last 30 years in HIV-infected patients and in the general population.

\section{Patients and Methods}

\subsection{Study Design, Study Population}

We performed a single-center, retrospective study of a cohort of patients diagnosed with anal ISCC. The cohort was selected from a database of patients attending a tertiary hospital (Hospital Germans Trias i Pujol in Badalona, Spain) from January 1983 to September 2012 (the first 30 years’ activity at our center). The hospital is a referral hospital for a catchment area of 800,000 inhabitants in Catalonia. In 2005, a screening program for HPVrelated diseases of the anal canal was initiated in our Clinical HIV Unit. The study was approved by the local ethics committee.

\subsection{Biopsy Processing and HPV Genotyping}

All patients diagnosed with anal ISCC were identified from histopathology records. Formaldehyde-fixed, paraffin-embedded specimens were recovered and processed for extraction of DNA and detection and typing of HPV. DNA was extracted from 1 to 3 of $10-\mu$ m sections using the Maxwell FFPE Tissue LEV DNA Purification kit (Promega Corporation, Madison, Wisconsin, USA) according to the manufacturer's instructions. HPV was de- 
tected and typed in all samples using a commercial IVD CE-marked assay in accordance with the manufacturer's instructions (F-HPV typing; Molgentix, Barcelona, Spain). Briefly, extracted DNA was amplified using a multiplex polymerase chain reaction (PCR) including a set of fluorescently labelled primers recognizing HPV-6, $11,16,18,31,33,35,39,45,51,52,53,56,58,59,66$, and 68 within the E6 and E7 regions of the HPV genome [12] [14].

\subsection{Statistical Analysis}

Since the study was an exploratory study, no formal sample size was calculated. The sample comprised all patients with a diagnosis of anal ISCC during the study period.

A descriptive and exploratory analysis was performed for baseline parameters (Table 1) and for HPV results (Table 2) to explore differences between the study groups (HIV-infected and non-HIV-infected). Data were analyzed using the statistical software program SPSS version 15.0 (SPSS Inc, Chicago, Illinois, USA).

\section{Results}

During the study period, 10 cases of anal ISCC were diagnosed in HIV-infected patients, as follows: 1 man (in 1999, no information about his sexual orientation), 4 MSM (1999, 2000, 2002, and 2009), 3 heterosexual men (2004, 2004 and 2010), 1 woman (2006), and 1 transsexual (2012). The median (range) age was 40 (32 - 59) years, and 5 patients had never received HAART. From 2005, 70\% of the current HIV population (1310 men, 208 women) agreed to participate in the screening program for HPV-related diseases of the anal canal. Of the 4 cases of anal ISCC diagnosed between 2005 and 2011, only 1 had participated in this screening program and had previously been treated for in situ anal SCC with surgery (1.5 years earlier). None of the HIV-infected patients had a history of anal condylomata.

During the same period, 21 cases were diagnosed in the general population (10 women, 11 men; 15 between 2005 and 2012 [5 women and 10 men]). The first case was diagnosed in 1988. The median (range) age was 58 (33 - 83) years. None of the HIV-negative cases had a history of intravenous drug use. Table 1 shows the baseline characteristics.

ISCC of the anal canal was diagnosed significantly earlier in men $(p=0.013)($ mean $=52$ years, median $=50$ years, $S D=14.5$ ) than in women (mean $=67$ years, median $=73, S D=13$ ). Although statistical differences

Table 1. Demographic characteristics of anal invasive squamous cell cancer (ISSC) in HIV-infected and non-HIV-infected individuals.

\begin{tabular}{|c|c|c|}
\hline & HIV-infected patients $(\mathrm{n}=10)$ & Non-HIV-infected patients $(\mathrm{n}=21)$ \\
\hline Proportion of men/women (n) & $9 / 1$ & $11 / 10$ \\
\hline \multicolumn{3}{|l|}{ Age at diagnosis of ISCC, years } \\
\hline Mean (SD): & $42(8.8)^{\mathrm{a}}$ & $60(16)^{a}$ \\
\hline \multicolumn{3}{|l|}{ Median (range): } \\
\hline Overall & $40(32-59)^{a}$ & $58(33-83)^{a}$ \\
\hline Men & $40(32-59)$ & $50(33-79)^{b}$ \\
\hline Women & Not applicable & $73(49-83)^{b}$ \\
\hline \multicolumn{3}{|l|}{ Sexual orientation, $\mathrm{n}(\%)$} \\
\hline MSM & $4(40)$ & - \\
\hline Heterosexual & $4^{*}(40)$ & - \\
\hline Transsexual & $1^{*}(10)$ & - \\
\hline Not recorded & $1(10)$ & $21(100)$ \\
\hline \multicolumn{3}{|l|}{ CD4 counts (cells $/ \mu \mathrm{L})$} \\
\hline Median (range) nadir & $104(0-603)$ & - \\
\hline Median (range) at diagnosis & $155(61-1122)$ & - \\
\hline
\end{tabular}

*Patients with history of intravenous drug use: heterosexuals ( 3 men and 1 woman) and a transsexual woman. MSM, men who have sex with men; ${ }^{\mathrm{a} O v e r a l l ~ d i f f e r e n c e s ~ s t a t i s t i c a l l y ~ s i g n i f i c a n t ~}(\mathrm{p}<0.01)$; ${ }^{\mathrm{b}}$ Gender differences statistically significant $(\mathrm{p}=0.013)$. 
Table 2. Results of anal invasive squamous cell cancer (ISCC) biopsies with single-type and multiple-type HPV infections.

\begin{tabular}{|c|c|c|}
\hline Human papillomavirus infection in anal ISCC & HIV-infected $(\mathrm{n}=8)^{*}$ & Non-HIV-infected $(\mathrm{n}=21)$ \\
\hline Any HPV infection, n (\%) & $7^{* *}(87.5)$ & $16(76.2)$ \\
\hline \multicolumn{3}{|l|}{ HPV-16, n (\%) } \\
\hline Single-type & $3(37.5)$ & $14(66.7 \%)$ \\
\hline Multiple-type & $1^{\mathrm{a}}(12.5)$ & 0 \\
\hline \multicolumn{3}{|l|}{ HPV-18, n (\%) } \\
\hline Single-type & 0 & $1(4.8)$ \\
\hline Multiple-type & 0 & 0 \\
\hline \multicolumn{3}{|l|}{ Other high-risk HPV, n (\%) } \\
\hline Single-type (excluding 16 and 18) & $2^{\mathrm{b}}(25)$ & $1^{\mathrm{d}}(4.8)$ \\
\hline Multiple-type (excluding 16 and 18) & $1^{\mathrm{c}}(12.5)$ & 0 \\
\hline \multicolumn{3}{|l|}{ Low-risk HPV, n (\%) } \\
\hline Multiple-type (containing HPV-6) & $1^{\mathrm{c}}(12.5)$ & 0 \\
\hline
\end{tabular}

"Patients diagnosed with ISCC whose biopsy specimen had not degraded. ${ }^{* *}$ One sample had no PCR amplification. ${ }^{\mathrm{a}}$ Patient with HPV-16 + HPV-66 coinfection; ${ }^{b}$ Two male patients with HPV-33 and HPV-51 respectively. ${ }^{\mathrm{c}}$ Man with HPV-6, HPV-52, and HPV-66. ${ }^{\mathrm{d}}$ Man with HPV-52.

were found in median age between the HIV-infected and non-HIV-infected populations ( $<$ < 0.01) (Table 1), no differences were observed with respect to HIV status after clustering for gender (HIV-infected men [mean $=42$ years, median $=40$ years, $\mathrm{SD}=8.8$ ] vs non-HIV-infected men [mean $=52$ years, median $=50$ years, $\mathrm{SD}=14.5$ ], $(\mathrm{p}=0.12)$.

Of the 31 cases of ISCC identified from the records (10 HIV-infected and 21 non-HIV-infected), 2 biopsies from the HIV-infected patients were not amplified by PCR because the DNA was degraded. HPV was therefore investigated in 29 samples (8 HIV-infected and 21 non-HIV-infected) and detected in 87.5\% of anal biopsy specimens (7 out of 8 ) in the HIV-infected patients and in $76.2 \%$ of specimens (16 out of 21) in the non-HIV-infected population (Table 2). No multiple-type infections were found in the non-HIV-infected population, whereas 2 HIV-infected patients (28.6\%, 2/7) presented 2 or more HPV types. The most prevalent type was HPV-16, mainly as a single-type infection, representing 50\% (4 out of 8) (57\% [4 out of 7] of the positive HPV infections) in the HIV-infected group and 66.7\% (14 out of 21) (87.5\% (14 out of 16) of the positive HPV infections) in the non-HIV-infected group. Infection by HPV-18 was detected in only 1 sample from a non-HIV-infected man. Other high-risk types (e.g., HPV-33, 51, 52, and 66) were also detected in 3 patients as a single-type infection and in 1 patient as a multiple-type infection. A low-risk type, HPV-6, was found in 1 specimen from an HIV-infected man, although it co-infected with other HR types (Table 2). In the HIV-infected group, 37.5\% of patients with ISCC (3 out of 8) had other HR-HPV types not included in the conventional vaccines, compared with $4.8 \%$ (1 out of 21 ) in the non-HIV-infected population. All cases of anal ISCC in HIV-infected patients were from the HAART era.

\section{Discussion}

This study provides new data about HPV infection in HIV-infected and non-HIV-infected patients with anal ISCC attended at an HIV reference hospital in Catalonia over a 30-year period. The prevalence of HPV DNA found in the anal cancer biopsies of these HIV-infected patients (87.5\%) was in the range reported in North America [1] [15] [16], Europe [17], and Australia [18], namely, 88\% to 97\%. In the non-HIV-infected group, the percentage of HPV-positive samples was lower (around 76\%) than reported elsewhere [19]. Differences between studies in the prevalence of HPV can be due to differences in the geographical region and the population studied (e.g., ethnicity and social and cultural background). Furthermore, the quality of conservation of histology samples and the techniques used for DNA extraction and HPV testing can considerably influence variability in prevalence. Consistent with other authors [1] [15], we found that HPV-18 was rare (only 1 case in a non-HIVinfected woman), thus reinforcing the fact that HPV-18 is more common in cervical cancer than in anal SCC [20]. Moreover, mean age at the diagnosis of anal ISCC was significantly lower for men than for women, as re- 
ported elsewhere [18]; however, we did not observe this effect of HIV infection on age, probably because of the small sample size and the composition of the HIV-infected group.

Differences in HPV type distribution according to HIV status have been reported [17] [21], and our data support these differences. HPV-16 was the most frequent type in the patients we studied regardless of HIV status, and basically as a single-type infection, as reported elsewhere [18] [19]. However, we found that HIV-infected patients had a higher proportion of multiple-type infections and HR types other than vaccine types (HPV-16 or -18) than non-HIV-infected patients. By contrast, we did not find differences in the prevalence of HPV-16 between the sexes, in contrast with reports from other authors, who found a lower frequency of HPV-16 in men than in women [1].

Our study is subject to a series of limitations. First, the small sample size could have affected the power to detect significant statistical differences for some characteristics. Second, the HPV typing assay used is only able to detect the most common types; consequently, other, more infrequent types may have gone undetected. Finally, a single-center study is not representative of the whole population of Spain. Nevertheless, ours is a reference center for clinical HIV therapy and admits a large number of HIV-infected patients.

\section{Conclusion}

In conclusion, HIV-infected patients seem to present anal ISCC with multiple HPV infections and with HRHPV types not covered by conventional vaccines. Genotyping of anal cancer specimens can help to determine the most critical types involved in this disease in a specific region and, consequently, to design optimal prophylactic HPV vaccines.

\section{Acknowledgements}

We are particularly grateful to the patients of our HIV Unit. The authors thank Thomas O'Boyle for editorial assistance.

\section{Funding}

This work was supported by grants from Red de Investigacion en SIDA (RIS), ART AIDS Foundation, Gilead Sciences, Obra Social Caixa Sabadell, and Gala contra la SIDA Barcelona 2011.

\section{Competing Interest}

None declared.

\section{References}

[1] Ouhoummane, N., Steben, M., Coutlée, F., Vuong, T., Forest, P., Rodier, C., Louchini, R., Duarte, E. and Brassard, P. (2013) Squamous Anal Cancer: Patient Characteristics and HPV Type Distribution. Cancer Epidemiology, 37, 807812. http://dx.doi.org/10.1016/j.canep.2013.09.015

[2] Joseph, D.A., Miller, J.W., Wu, X., Chen, V.W., Morris, C.R., Goodman, M.T., Villalon-Gomez, J.M., Williams, M.A. and Cress, R.D. (2008) Understanding the Burden of Human Papillomavirus Associated Anal Cancers in the US. Cancer, 113, 2892-2900. http://dx.doi.org/10.1002/cncr.23744

[3] Jin, F., Stein, A.N., Conway, E.L., Regan, D.G., Law, M., Brotherton, J.M., Hocking, J. and Grulich, A.E. (2011) Trends in Anal Cancer in Australia, 1982-2005. Vaccine, 29, 2322-2327. http://dx.doi.org/10.1016/j.vaccine.2011.01.015

[4] Nielsen, A., Munk, C. and Kjaer, S.K. (2012) Trends in Incidence of Anal Cancer and High-Grade Anal Intraepithelial Neoplasia in Denmark, 1978-2008. International Journal of Cancer, 130, 1168-1173. http://dx.doi.org/10.1002/ijc.26115

[5] Palefsky, J.M., Holly, E.A., Ralston, M.L., Arthur, S.P., Jay, N., Berry, J.M., Da Costa, M.M., Botts, R. and Darragh, T.M. (1998) Anal Squamous Intraepithelial Lesions in HIV-Positive and HIV-Negative Homosexual and Bisexual Men: Prevalence and Risk Factors. Journal of Acquired Immune Deficiency Syndromes and Human Retrovirology, 17, 320326. http://dx.doi.org/10.1097/00042560-199804010-00005

[6] Piketty, C., Darragh, T.M., Da Costa, M., Bruneval, P., Heard, I., Kazatchkine, M.D. and Palefsky, J.M. (2003) High Prevalence of Anal Human Papillomavirus Infection and Anal Cancer Precursors among HIV Infected Persons in the 
Absence of Anal Intercourse. Annals of Internal Medicine, 138, 453-459.

http://dx.doi.org/10.7326/0003-4819-138-6-200303180-00008

[7] Frisch, M., Biggar, R.J. and Goedert, J.J. (2000) Human Papillomavirus-Associated Cancers in Patients with Human Immunodeficiency Virus Infection and Acquired Immunodeficiency Syndrome. Journal of the National Cancer Institute, 92, 1500-1510. http://dx.doi.org/10.1093/jnci/92.18.1500

[8] Ahmed, S. and Eng, C. (2014) Optimal Treatment Strategies for Anal Cancer. Current Treatment Options in Oncology, 15, 443-455. http://dx.doi.org/10.1007/s11864-014-0298-0

[9] Berry, J.M., Jay, N., Cranston, R.D., Darragh, T.M., Holly, E.A., Welton, M.L. and Palefsky, J.M. (2014) Progression of Anal High-Grade Squamous Intraepithelial Lesions to Invasive Anal Cancer among HIV-Infected Men Who Have Sex with Men. International Journal of Cancer, 134, 1147-1155. http://dx.doi.org/10.1002/ijc.28431

[10] van der Loeff, M.F.S., Mooij, S.H., Richel, O., de Vries, H.J. and Prins, J.M. (2014) HPV and Anal Cancer in HIV-Infected Individuals: A Review. Current HIV/AIDS Reports, 11, 250-262. http://dx.doi.org/10.1007/s11904-014-0224-x

[11] Glynne-Jones, R., Nilsson, P.J., Aschele, C., Goh, V., Peiffert, D., Cervantes, A. and Arnold, D. (2014) Anal Cancer: ESMO-ESSO-ESTRO Clinical Practice Guidelines for Diagnosis, Treatment and Follow-Up. Radiotherapy and Oncology, 111, 330-339. http://dx.doi.org/10.1016/j.radonc.2014.04.013

[12] Darwich, L., Videla, S., Cañadas, M.P., Piñol, M., García-Cuyàs, F., Vela, S., Molina-López, R.A., Coll, J., Sirera, G. and Clotet, B. (2013) Distribution of Human Papillomavirus Genotypes in Anal Cytological and Histological Specimens from HIV-Infected Men Who Have Sex with Men and Men Who Have Sex with Women. Diseases of the Colon \& Rectum, 56, 1043-1052. http://dx.doi.org/10.1097/DCR.0b013e31829c654f

[13] Videla, S., Darwich, L., Cañadas, M.P., Coll, J., Piñol, M., García-Cuyás, F., Molina-Lopez, R.A., Cobarsi, P., Clotet, B. and Sirera, G. (2013) Natural History of Human Papillomavirus Infections Involving Anal, Penile, and Oral Sites among HIV-Positive Men. Sexually Transmitted Diseases, 40, 3-10. http://dx.doi.org/10.1097/OLQ.0b013e31827e87bd

[14] Villa, L.L. (2011) HPV Prophylactic Vaccination: The First Years and What to Expect from Now. Cancer Letters, 305, 106-112. http://dx.doi.org/10.1016/j.canlet.2010.12.002

[15] Wong, A.K., Chan, R.C., Aggarwal, N., Singh, M.K., Nichols, W.S. and Bose, S. (2010) Papillomavirus Genotypes in Anal Intraepithelial Neoplasia and Anal Carcinoma as Detected in Tissue Biopsies. Modern Pathology, 23, 144-150. http://dx.doi.org/10.1038/modpathol.2009.143

[16] Daling, J.R., Madeleine, M.M., Johnson, L.G., Schwartz, S.M., Shera, K.A., Wurscher, M.A., Carter, J.J., Porter, P.L., Galloway, D.A. and McDougall, J.K. (2004) Human Papillomavirus, Smoking, and Sexual Practices in the Etiology of anal Cancer. Cancer, 101, 270-280. http://dx.doi.org/10.1002/cncr.20365

[17] Abramowitz, L., Jacquard, A.C., Jaroud, F., Haesebaert, J., Siproudhis, L., Pradat, P., Aynaud, O., Leocmach, Y., Soubeyrand, B., Dachez, R., Riethmuller, D., Mougin, C., Pretet, J.L. and Denis, F. (2011) Human Papillomavirus Genotype Distribution in Anal Cancer in France: The EDiTH V Study. International Journal of Cancer, 129, 433-439. http://dx.doi.org/10.1002/ijc.25671

[18] Hillman, R.J., Garland, S.M., Gunathilake, M.P., Stevens, M., Kumaradevan, N., Lemech, C., Ward, R.L., Meagher, A., McHugh, L., Jin, F., Carroll, S., Goldstein, D., Grulich, A.E. and Tabrizi, S.N. (2014) Short Report; Human Papillomavirus (HPV) Genotypes in an Australian Sample of Anal Cancers. International Journal of Cancer, 135, 996-1001. http://dx.doi.org/10.1002/ijc.28730

[19] Alemany, L., Saunier, M., Alvarado-Cabrero, I., Quirós, B., Salmeron, J., Shin, H.R., Pirog, E.C., Guimerà, N., Hernandez-Suarez, G., Felix, A., Clavero, O., Lloveras, B., Kasamatsu, E., Goodman, M.T., Hernandez, B.Y., Laco, J., Tinoco, L., Geraets, D.T., Lynch, C.F., Mandys, V., Poljak, M., Jach, R., Verge, J., Clavel, C., Ndiaye, C., Klaustermeier, J., Cubilla, A., Castellsagué, X., Bravo, I.G., Pawlita, M., Quint, W.G., Muñoz, N., Bosch, F.X. and de Sanjosé, S. (2014) HPV DNA Prevalence and Type Distribution in Anal Carcinomas Worldwide. International Journal of Cancer, Early View. http://dx.doi.org/10.1002/ijc.28963

[20] Darwich, L., Cañadas, M.P., Sirera, G., Alameda, F., Forcada, P., Delas, J., Fernández, I., Llatjós, M., Coll, J., Clotet, B. and Videla, S. (2011) Human Papillomavirus Genotype Distribution and Human Papillomavirus 16 and Human Papillomavirus 18 Genomic Integration in Invasive and in Situ Cervical Carcinoma in Human Immunodeficiency VirusInfected Women. International Journal of Gynecological Cancer, 21, 1486-1490. http://dx.doi.org/10.1097/IGC.0b013e31822a0195

[21] De Vuyst, H., Clifford, G.M., Nascimento, M.C., Madeleine, M.M. and Franceschi, S. (2009) Prevalence and Type Distribution of Human Papillomavirus in Carcinoma and Intraepithelial Neoplasia of the Vulva, Vagina and Anus: A Meta-Analysis. International Journal of Cancer, 124, 1626-1636. http://dx.doi.org/10.1002/ijc.24116 
Scientific Research Publishing (SCIRP) is one of the largest Open Access journal publishers. It is currently publishing more than 200 open access, online, peer-reviewed journals covering a wide range of academic disciplines. SCIRP serves the worldwide academic communities and contributes to the progress and application of science with its publication.

Other selected journals from SCIRP are listed as below. Submit your manuscript to us via either submit@scirp.org or Online Submission Portal.
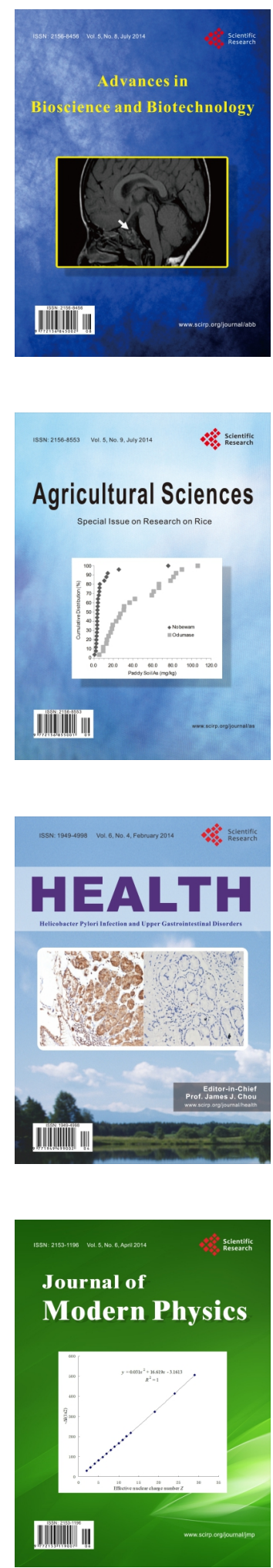
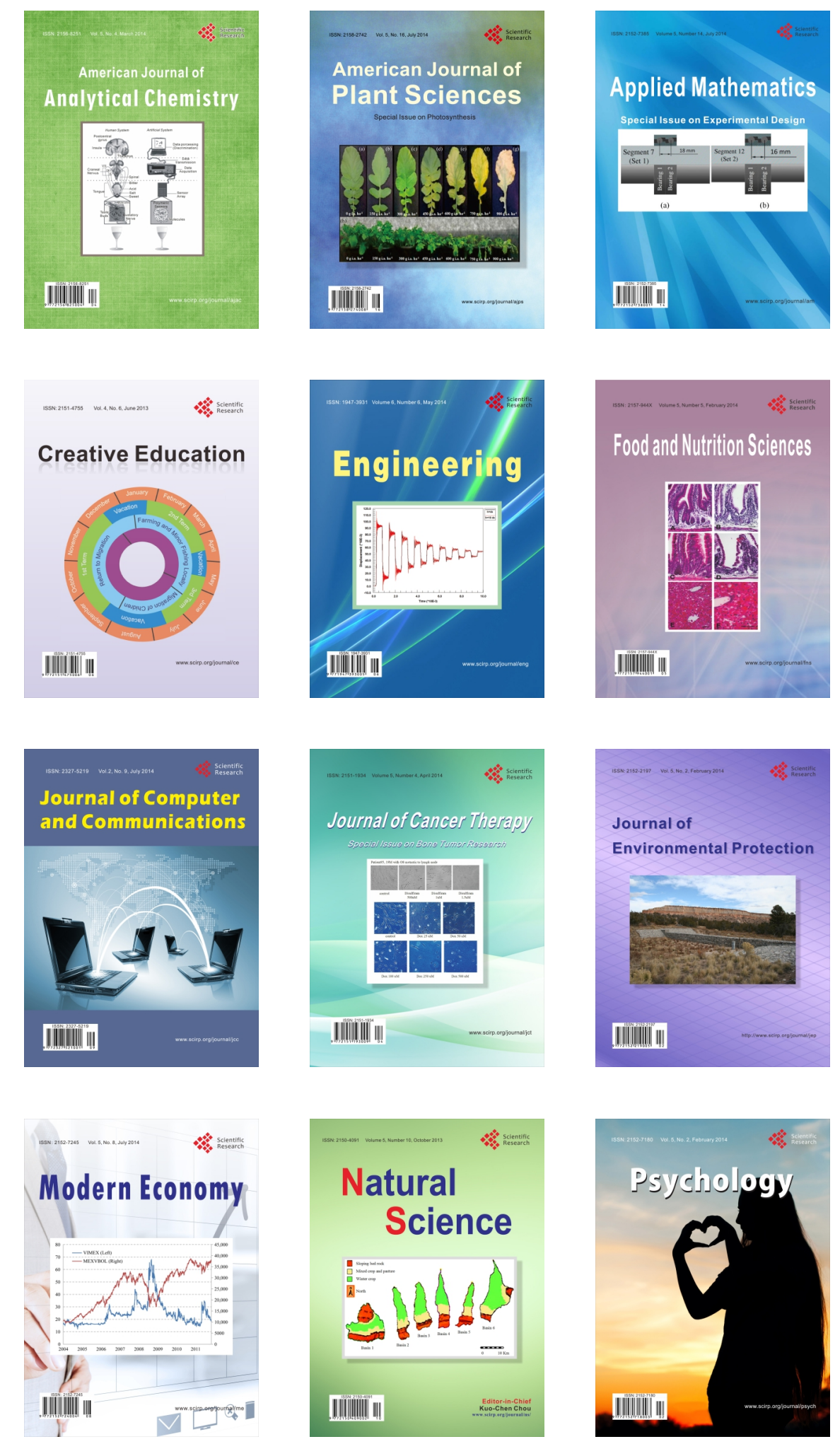